\title{
Bromocriptine-induced premature oestrus is associated with changes in the pulsatile secretion pattern of follicle-stimulating hormone in beagle bitches
}

\author{
H. S. Kooistra ${ }^{1}$, A. C. Okkens ${ }^{1}$, M. M. Bevers ${ }^{2}$, C. Popp-Snijders ${ }^{3}$, B. van Haaften ${ }^{1}$, \\ S. J. Dieleman ${ }^{2}$ and J. Schoemaker ${ }^{3}$ \\ ${ }^{1}$ Department of Clinical Sciences of Companion Animals, and ${ }^{2}$ Department of Herd Health and Reproduction, Faculty of Veterinary \\ Medicine, Utrecht University, 3508 TD Utrecht, The Netherlands; and ${ }^{3}$ Research Institute for Endocrinology, Reproduction and \\ Metabolism, University Hospital, Vrije Universiteit Medical Center, 1007 MB Amsterdam, The Netherlands
}

\begin{abstract}
The secretory profiles of LH and FSH were investigated before and during the administration of bromocriptine in six beagle bitches. Plasma samples were obtained via jugular venepuncture at $10 \mathrm{~min}$ intervals for $6 \mathrm{~h}$ every 2 weeks until the next ovulation. Bromocriptine treatment was started 100 days after ovulation. Both before and after bromocriptine treatment, LH and FSH pulses occurred together. The mean duration of the FSH pulse (120 min) was significantly longer than that of the LH pulse $(80 \mathrm{~min})$. The interoestrous interval in the bitches treated with bromocriptine was significantly shorter than that of the preceding cycle ( $160 \pm 3$ versus $206 \pm 24$ days). The mean basal plasma FSH concentration $\left(7.4 \pm 0.6\right.$ versus $\left.6.1 \pm 0.7 \mathrm{iu} \mathrm{l} \mathrm{l}^{-1}\right)$ and the mean area under the curve for FSH $\left(46.6 \pm 4.7\right.$ versus $40.4 \pm 4.4$ iu l $^{-1}$ in $\left.6 \mathrm{~h}\right)$ increased significantly after the start of the bromocriptine treatment. In contrast, the differences in mean basal plasma LH concentration $\left(2.1 \pm 0.2\right.$ versus $\left.2.0 \pm 0.2 \mu \mathrm{g} \mathrm{l}^{-1}\right)$ and the mean area under the curve for $\mathrm{LH}\left(19.0 \pm 3.1\right.$ versus $19.5 \pm 2.5 \mu \mathrm{g} \mathrm{l}^{-1}$ in $\left.6 \mathrm{~h}\right)$ between the day before and 14 days after the start of the bromocriptine treatment were not significant. Bromocriptine administration also lowered the mean amplitude of the FSH pulse and shortened the mean duration of the FSH pulse, without influencing the LH pulse. In addition to demonstrating the concurrent pulsatile secretion of $\mathrm{LH}$ and $\mathrm{FSH}$, the results of the present study demonstrate that the bromocriptine-induced shortening of the interoestrous interval in the bitch is associated with an increase in plasma FSH concentration without a concomitant increase in plasma LH concentration. This finding indicates that treatment with the dopamine agonist bromocriptine increases plasma FSH to a concentration that results in the enhancement of follicle development.
\end{abstract}

\section{Introduction}

The oestrous cycle of the Canidae differs considerably from that of other species. Most studies have been performed in domestic bitches, in which the follicular phase and spontaneous ovulations are followed by a luteal phase with an average duration of about 75 days (Schaefers-Okkens, 1996). A non-seasonal anoestrus of variable duration (2-10 months) follows each oestrous cycle (Bouchard et al., 1991; Concannon, 1993). Endocrine changes leading to termination of anoestrus and the start of a new follicular phase in bitches are poorly understood.

Progression from early to late anoestrus is associated with an increase in the basal plasma FSH concentration, indicating

Received 18 February 1999 that, in bitches, an increase in circulating FSH concentrations is a critical event in the initiation of ovarian folliculogenesis (Kooistra et al., 1999). An increasing release of GnRH by the hypothalamus (Tani et al., 1996) and an increase in the sensitivity of the pituitary to GnRH from early to late anoestrus (Van Haaften et al., 1994) have also been observed in this species. In addition, an increase in ovarian responsiveness to gonadotrophins (Jeffcoate, 1993), increased circulating basal $\mathrm{LH}$ concentrations at the end of anoestrus (Olson et al., 1982) and a brief period of increased LH pulsatility (Concannon et al., 1986) are important determinants of the initiation of a new follicular phase. It has even been suggested that changes in LH secretion may be more important than changes in FSH secretion in the initiation of a follicular phase leading to ovulation (Concannon, 1993). In line with this suggestion, the 
administration of pharmacological doses of LH alone can terminate anoestrus by inducing a follicular phase in bitches (Verstegen et al., 1997).

In addition to these changes in the hypothalamuspituitary-gonad axis, there is evidence of involvement of dopaminergic influences and prolactin release. Administration of the dopamine 2 receptor agonists, bromocriptine and cabergoline, during both the luteal phase and anoestrus results in shortening of the interoestrous interval (Okkens et al., 1985a; Van Haaften et al., 1989; Concannon, 1993; Onclin et al., 1995). The shortened interoestrous interval is the result of a shortening of the duration of both the luteal phase (Okkens et al., 1985a; Okkens et al., 1990) and anoestrus (Okkens et al., 1985a; Concannon, 1993). It has been hypothesized that the dopamine 2 agonist-induced shortening of the interoestrous interval is the result of the suppression of prolactin secretion. Indeed, in humans, it has been demonstrated that high concentrations of prolactin inhibit GnRH pulsatility (Saunder et al., 1984; Yazigi et al., 1997). Studies in several other mammalian species have also demonstrated that hyperprolactinaemia is associated with decreased gonadotrophin secretion (Bevers et al., 1983; Park and Selmanoff, 1993; Park et al., 1993; Jedlinska et al., 1995). Lowering of the plasma prolactin to basal concentrations is usually associated with the return of gonadotrophic pulsatility (Bevers et al., 1983; Saunder et al., 1984).

However, under physiological conditions, no obvious changes in plasma concentrations of prolactin have been observed in bitches during the transition from anoestrus to the follicular phase (Olson et al., 1982). In addition, administration of metergoline, a 5-hydroxytryptamine (serotonin) receptor antagonist, to anoestrous bitches in a dose resulting in plasma prolactin concentrations even lower than those during bromocriptine treatment did not shorten the interoestrous interval (Okkens et al., 1997). These observations indicate that the induction of the follicular phase is not initiated by the suppression of prolactin secretion, but by other direct or indirect dopaminergic effects. The present study investigated the pulsatile patterns of secretion of LH and FSH during bromocriptine-induced transition from anoestrus to the follicular phase in bitches to improve understanding of the interaction between dopaminergic influences and gonadotrophin release.

\section{Materials and Methods}

\section{Animals, treatment, and collection of blood samples}

Six healthy beagle bitches, 1.5-5.0 years of age, were used in this study. All bitches had been born and raised in the Department of Clinical Sciences of Companion Animals and were accustomed to the laboratory environment and procedures such as collection of blood. They were housed singly or in pairs in indoor-outdoor runs, fed a standard commercial dog food once a day, and given water ad libitum.

All bitches were examined three times a week for the presence of swelling of the vulva and a serosanguinous vaginal discharge, which were considered to signify the onset of pro-oestrus. Plasma concentrations of progesterone were determined three times per week from the start of prooestrus until the day at which the plasma progesterone concentration exceeded $16 \mathrm{nmol} \mathrm{I}^{-1}$, which is when ovulation was assumed to occur (Concannon et al., 1977; Wildt et al., 1979; Okkens et al., 1985a).

The bitches were treated with $20 \mu \mathrm{g}$ bromocriptine (Lactafal ${ }^{\mathrm{R}}$, a gift from Eurovet, Bladel) per kg body weight orally, twice a day, starting $100 \pm 2$ (mean \pm SD) days after ovulation. Two bitches were treated after the first ovulation, consequently data on the duration of the preceding interoestrous interval were not available. The $6 \mathrm{~h}$ secretory profiles of $\mathrm{LH}$ and FSH from each bitch were determined the day before (day 0 ) and every 2 weeks after the start of the treatment with bromocriptine until the next ovulation or for a maximum of six times. Blood samples were collected from the jugular vein between 08:00 and 14:00 h at $10 \mathrm{~min}$ intervals, immediately placed in chilled heparin-coated tubes, and centrifuged for $10 \mathrm{~min}$ at $2000 \mathrm{~g}$. Plasma was stored at $-25^{\circ} \mathrm{C}$ until assayed.

\section{Hormone determinations}

Plasma LH concentrations were determined by a heterologous radioimmunoassay as described by Nett $e t$ al. (1975). A rabbit antiserum raised against ovine LH (CSU-204; kindly supplied by G. D. Niswender, Colorado State University), radio-iodinated NIAMDD-bLH-4, and canine pituitary standard LER 1685-1 (a gift from L. E. Reichert, Albany Medical College, NY) were used in this assay. The intra-assay and interassay coefficients of variation for values above $0.5 \mu \mathrm{g} \mathrm{l}^{1-1}$ were 2.3 and $10.5 \%$, respectively. The lowest detectable concentration of $\mathrm{LH}$ was $0.3 \mu \mathrm{g} \mathrm{l^{-1 }}$.

Plasma FSH concentrations were determined by applying a human immunometric sandwich assay (Amerlite, Amersham, Bucks), validated for bitches (Kooistra et al., 1999). Results are expressed in units of a human FSH standard ( $2^{\text {nd }}$ International Reference Preparation (IRP) 78/549). Values of FSH measured with the Amerlite assay in serum, EDTA plasma, or heparin plasma from bitches were similar. Values of FSH measured with the Amerlite assay after serial dilution of various bitch samples showed good linearity down to a concentration of 0.5 iu $\mathrm{I}^{-1}$, indicating that, in this assay, the immunochemistry of bitch FSH is similar to that of the human FSH standards. The sensitivity of the assay was $0.5 \mathrm{iu} \mathrm{l}^{-1}$. The intra-assay coefficient of variation was $<5 \%$. The interassay coefficients of variation were $5 \%$ at a concentration of $35 \mathrm{iu} \mathrm{l}^{-1}$ and $9 \%$ at a concentration of $3 \mathrm{iu} \mathrm{1}^{-1}$. Recovery of human FSH (assay standard preparation) added to bitch samples was $103 \%$. Possible crossreactivity of bitch LH in the FSH assay was tested by analysing the canine pituitary standard LER 1685-1, purified by L. E. Reichert, in the FSH assay. The purified canine pituitary LH standard showed an apparent crossreactivity in the FSH assay. However, this apparent crossreactivity was probably due to a contamination of the $\mathrm{LH}$ preparation with bitch FSH, as judged from the perfect parallelism of the LH preparation in the FSH assay. Even if the crossreactivity is considered genuine, the contribution of an LH peak value to a concomitant FSH peak value was $<10 \%$ of 
the FSH value. Plasma from hypophysectomized bitches

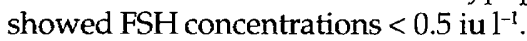

Plasma concentrations of progesterone were determined by a previously validated radioimmunoassay (Dieleman and Schoenmakers, 1979; Okkens et al., 1985b). The intra-assay and interassay coefficients of variation were $11 \%$ and $14 \%$, respectively. The lowest detectable concentration was 0.13 nmol l-1.

\section{Data analysis}

Plasma concentrations of $\mathrm{LH}$ were determined in all samples and plasma concentrations of FSH were determined in plasma samples at $10 \mathrm{~min}$ intervals in two bitches and at 20 min intervals in the other four bitches.

The pattern of pulses in the $6 \mathrm{~h}$ profiles of FSH and $\mathrm{LH}$ was analysed by means of the Pulsar programme developed by Merriam and Wachter (1982). The programme identifies secretory peak values by height and duration from a smoothed baseline, using the assay SD as a scale factor. The cut-off parameters G1-G5 of the Pulsar programme were set at $3.98,2.40,1.68,1.24$ and 0.93 times the assay SD as criteria for accepting peaks $1,2,3,4$ and 5 points wide, respectively. The smoothing time, a window used to calculate a running mean value omitting peak values, was set at $4 \mathrm{~h}$. The splitting cut-off parameter was set at 2.7 and the weight assigned to peak values was 0.05 . The A, B, and C values of the Pulsar programme, used to calculate the variance of the assay, were set at $\mathrm{A}=0, \mathrm{~B}=10.5$ and $\mathrm{C}=0$ for the $\mathrm{LH}$ assay and $\mathrm{A}=0, \mathrm{~B}=$ 5 and $C=0$ for the FSH assay. The values extracted from the Pulsar analyses included the mean of the smoothed baseline, the mean peak amplitude, the pulse frequency, the mean pulse duration, and the area under the curve (AUC). The AUC was calculated above the zero level.

Differences in the duration of LH and FSH pulses and changes in the parameters of the secretory patterns immediately before and 14 days after the start of the bromocriptine treatment were evaluated by unpaired or, if appropriate, paired two-tailed Student's $t$ tests. Next, changes in the parameters of the secretory patterns during the first 6 weeks of bromocriptine treatment were evaluated by one-way analysis of variance (ANOVA) or, if appropriate, ANOVA for repeated measures for main effect of duration of bromocriptine treatment. Subsequently, multiple comparisons were performed for data with significant $(P \leq 0.05)$ main effect using the Student-Newman-Keuls test or, when day 0 was used as the control group, using the Dunnett test. Differences in the duration of the interoestrous intervals were compared using Wilcoxon's signed rank test and differences in pulse frequency were analysed using the Friedman test, with multiple comparisons performed using the Dunnett test. Values are expressed as mean \pm SEM or as mean and range. $P \leq 0.05$ was considered significant.

\section{Ethics of experimentation}

This study was approved by the Ethical Committee of the Faculty of Veterinary Medicine, Utrecht University.

\section{Results}

The interoestrous interval in the bitches treated with bromocriptine was significantly shorter than in their preceding cycle ( $160 \pm 3$ versus $206 \pm 24$ days; $n=4)$. The interoestrous interval was also significantly shorter than that in another group of six beagle bitches in the dog colony, in which the interoestrous interval was assessed during approximately the same period ( $225 \pm 16$ days). In two bitches, ovulation occurred after the fourth sample collection (day 42) for the $6 \mathrm{~h}$ secretory profiles of LH and FSH whereas, in two other bitches, it occurred after the fifth sampling period (day 56). In the remaining two bitches, six secretory profiles were determined.

Both LH and FSH were secreted in a pulsatile fashion, although LH and FSH pulses could not be detected in all $6 \mathrm{~h}$ profiles (Fig. 1). Thirty-one LH pulses were identified by the Pulsar programme in the $6 \mathrm{~h}$ profiles of the six bitches. Each LH pulse coincided with an increase in plasma FSH concentration, but only 28 of the latter were recognized as significant FSH pulses by the Pulsar programme. There were no FSH pulses without a concurrent significant $\mathrm{LH}$ pulse. The basal plasma LH concentration was low compared with the maximum peak concentrations, whereas FSH pulses were characterized by relatively low peak values compared with the basal plasma FSH concentration. Both LH and FSH pulses were characterized by a rapid increase and a slow decrease in plasma $\mathrm{LH}$ concentration and, even more pronounced, in plasma FSH concentrations (Fig. 1). The mean duration of the FSH pulse $(120 \pm 5 \mathrm{~min})$ was significantly longer than that of the LH pulse $(80 \pm 2 \mathrm{~min})$.

In all bitches, both basal plasma FSH concentration and the AUC for FSH increased after the start of the bromocriptine treatment. The mean basal plasma FSH concentrations at 14,28 and 42 days after the start of the bromocriptine treatment were significantly higher than that at the day before the onset of treatment (Fig. 2). The mean AUC for FSH at 14 days after the start of the bromocriptine treatment was significantly higher than that before treatment. Differences in mean basal plasma $\mathrm{FSH}$ concentration and differences in the mean AUC for FSH at 14, 28 and 42 days after the start of the bromocriptine treatment were not significant (Table 1). Differences in mean basal plasma LH concentration and differences in the mean AUC for LH between the day before and 14 days after the start of the bromocriptine treatment were not significant. However, 28 days after the start of the bromocriptine treatment, the mean AUC for LH was significantly higher than that in the other periods, whereas the mean basal plasma LH concentration on day 28 did not differ significantly from the values in the other periods (Table 1).

The frequency of LH and FSH pulses did not differ significantly before and during bromocriptine treatment. However, the mean duration of the FSH pulse before treatment was significantly longer than that at 14,28 and 42 days after the start of the bromocriptine treatment. In agreement with this observation, the mean amplitude of the FSH pulse before treatment was significantly higher than that at 14 and 28 days after the start of bromocriptine treatment. Differences in the mean duration and the mean amplitude of the LH pulse between the day before and 14, 28 

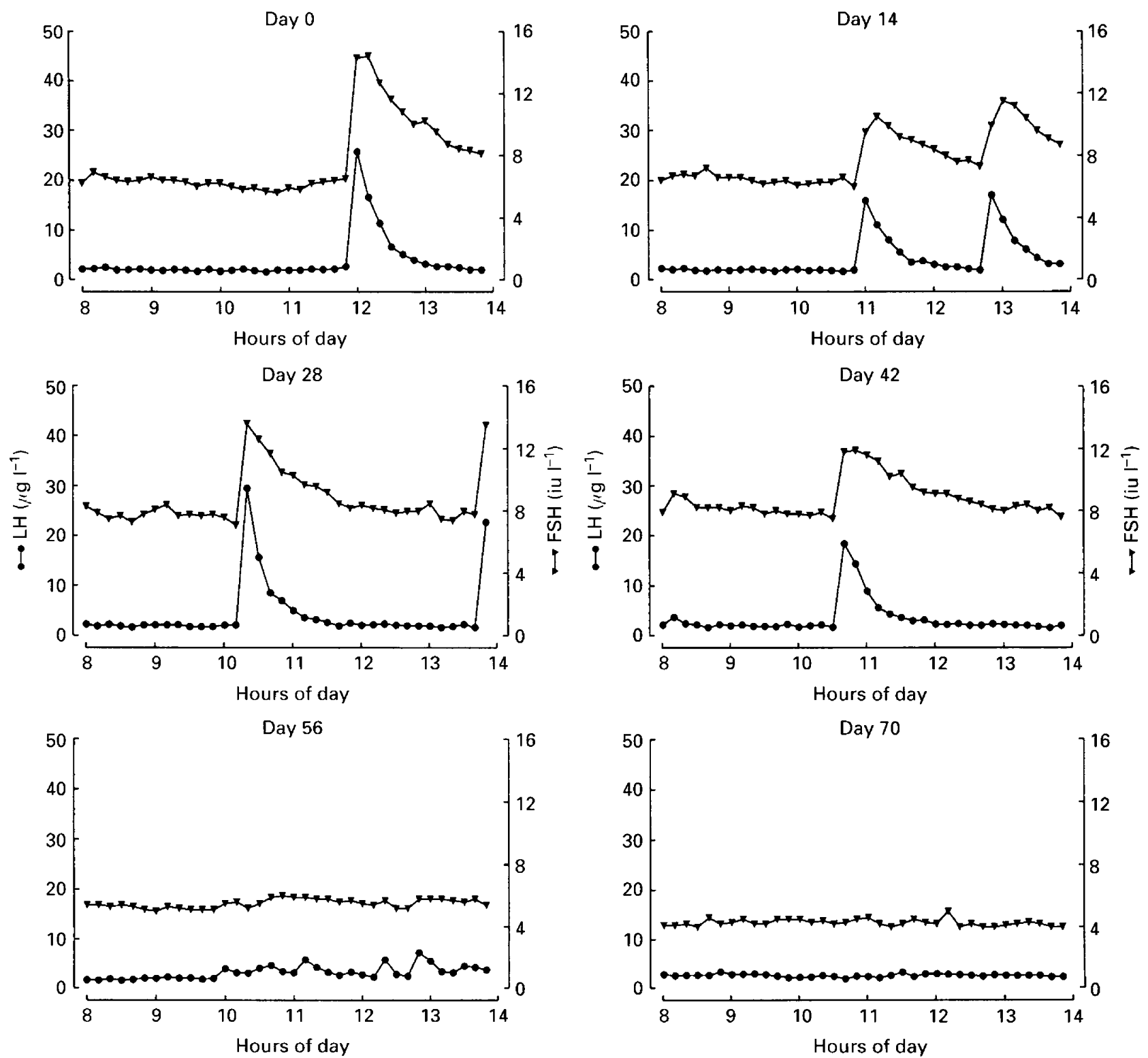

Fig. 1. The secretory profiles of FSH $(\nabla)$ and $\mathrm{LH}(\mathbf{O})$ in a 4-year-old beagle bitch. Blood samples were collected at $10 \mathrm{~min}$ intervals for $6 \mathrm{~h}$ on the day before (day 0) and every 2 weeks after the start of the treatment with bromocriptine (days 14-70). Ovulation occurred on day 74 .

and 42 days after the start of the bromocriptine treatment were not significant (Table 1 ).

In two bitches, one of the $6 \mathrm{~h}$ secretory profiles of LH was characterized by frequent increases of short duration (for example, see day 56 of Fig. 1). However, these increases were often too small to be recognized as significant pulses by the Pulsar programme. In both bitches, this typical $6 \mathrm{~h}$ secretory profile of LH was observed a few days before the onset of pro-oestrus and 14 days before the assumed day of ovulation. In two bitches, sampled 56 days after the start of the bromocriptine treatment, the $6 \mathrm{~h}$ secretory profiles of $\mathrm{LH}$ and FSH were determined during pro-oestrus. In both bitches, these $6 \mathrm{~h}$ secretory profiles were characterized by the absence of significant LH and FSH pulses and relatively low basal plasma FSH concentration.

\section{Discussion}

As the bromocriptine-induced shortening of the interoestrous interval in bitches can probably not be explained by suppression of prolactin secretion (Okkens $e t$ al., 1997), the present study investigated whether the induction of the follicular phase in this species might be initiated by other direct or indirect dopaminergic effects. The effects of administration of bromocriptine on the pulsatile patterns of secretion of LH and FSH were studied, taking into account the essential role of the gonadotrophins in the induction of a follicular phase. The results demonstrate that the bromocriptine-induced shortening of the interoestrous interval in bitches is associated with an increase in both the basal plasma FSH concentration and the AUC for FSH, 

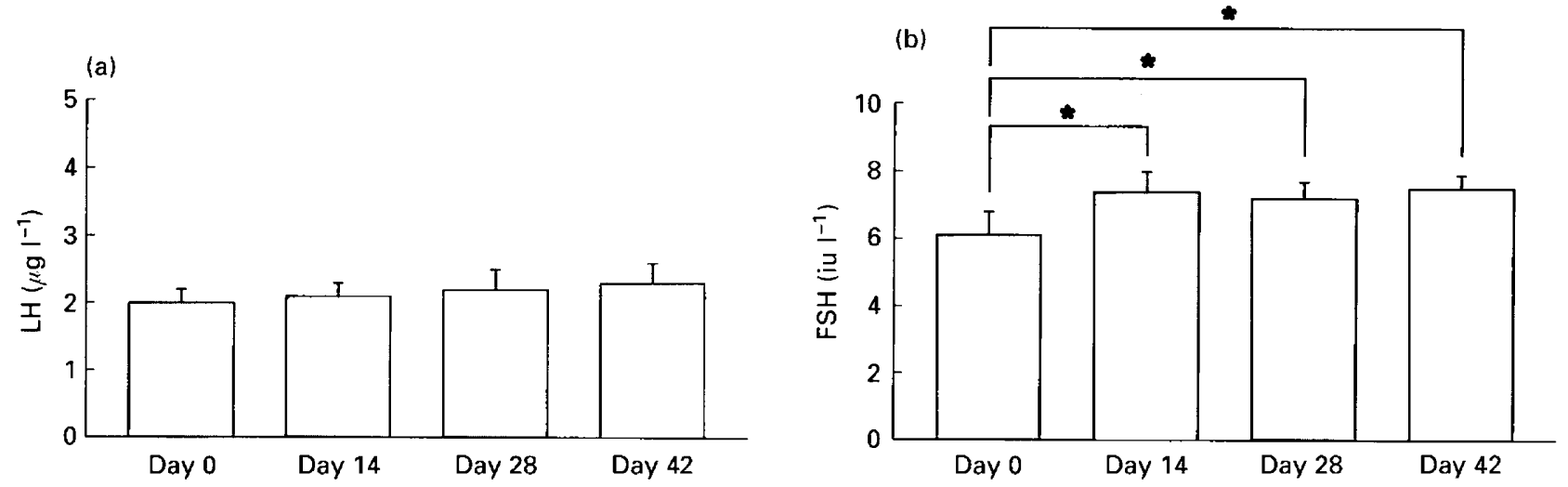

Fig. 2. The mean ( \pm SEM) plasma (a) LH and (b) FSH concentrations of the smoothed baseline in six beagle bitches the day before and 14,28 and 42 days after the start of bromocriptine treatment. Asterisks indicate significant difference $(P<0.05)$.

Table 1. Pulse characteristics of the $6 \mathrm{~h}$ secretory profiles of FSH and LH in six healthy beagle bitches treated with bromocriptine, starting 100 days after ovulation

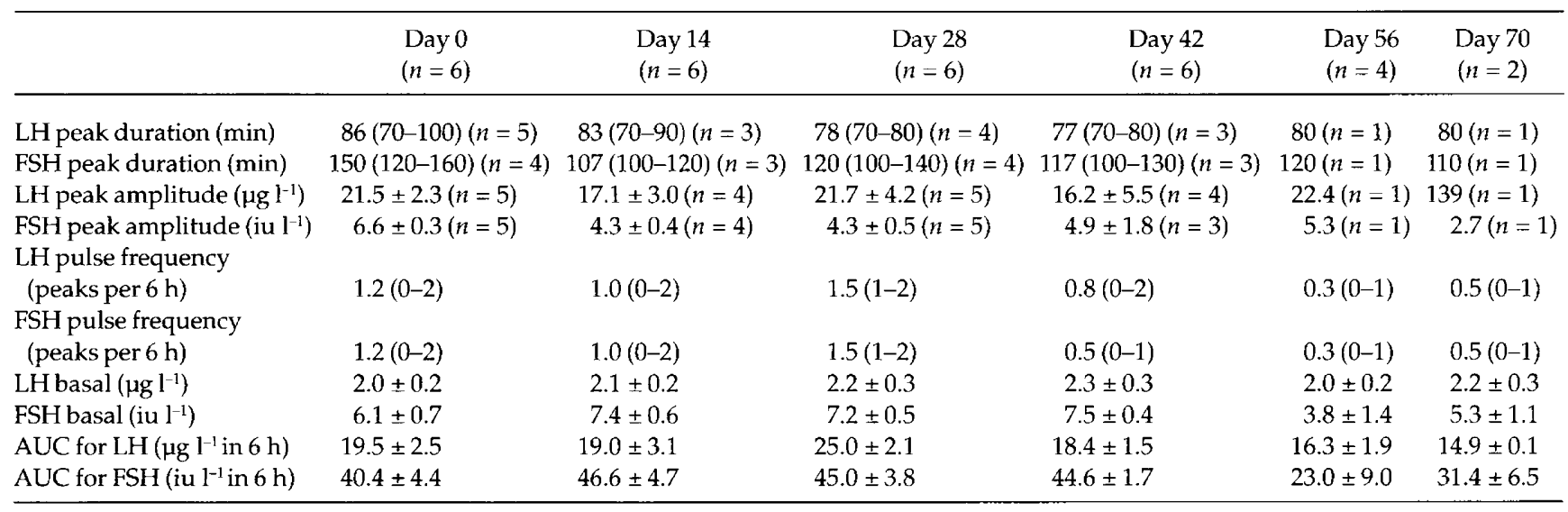

The secretory profiles were determined the day before (day 0 ) and every 2 weeks after the start of the treatment until the next ovulation. The values are expressed as mean $\pm \mathrm{SEM}$ or mean (and range).

AUC: area under curve; $n$ : the number of bitches in which a parameter could be determined.

without a concomitant increase in the basal plasma $\mathrm{LH}$ concentration and the AUC for LH. This finding gives further support to the notion that an increase in circulating FSH should be considered to be a critical event required for ovarian folliculogenesis in bitches (Kooistra et al., 1999). In this respect, there are similarities with the situation in primates. Observations during gonadotrophin-induced ovulation in women have emphasized that plasma FSH must exceed a certain concentration before preantral follicles reaching the $\mathrm{FSH}$-dependent stage can progress to maturation (Brown, 1978; Schoemaker et al., 1993). This has been named 'the FSH threshold concept'. Increases in plasma FSH concentrations only $10-30 \%$ above the threshold concentration are sufficient to stimulate normal follicular development in women (Brown, 1978). The threshold for FSH may vary among individuals, and each follicle also has its own sensitivity to FSH (Schoemaker et al., 1993). The increase in basal plasma FSH concentration during the progression of anoestrus (Kooistra et al., 1999) and the fact that the bromocriptine-induced shortening of the interoestrous interval is associated with an increase in plasma FSH concentration indicate that, analogous to the situation in women, an FSH threshold concept can also be postulated in bitches. If this is the case, dopamine 2 receptor agonists directly or indirectly increase plasma FSH concentration above the concentration that results in an enhancement of follicle development.

In the course of the bromocriptine treatment, that is, during progression of follicular development, plasma FSH concentrations decreased again. This was most obvious in two bitches in which the secretory profiles of LH and FSH were determined during pro-oestrus, that is, during the follicular phase. In agreement with earlier observations (Olson et al., 1982; Kooistra et al., 1999), the basal plasma FSH concentrations in these bitches were relatively low during this phase. As has been observed in other species, this finding is probably attributable to negative feedback effects of oestradiol and the ovarian peptides, inhibin and follistatin (Shupnik, 1996). The decreasing FSH release will prevent further development of other follicles in which the threshold 
concentration has not yet been surpassed and, consequently, will prevent the development of an excessive number of preovulatory follicles. The largest and foremost follicles may escape the atretic effect of the decreasing plasma FSH concentration because of an increased sensitivity to FSH (Zeleznik and Kubik, 1986).

With regard to the pulsatile secretion pattern of $\mathrm{LH}$, the most remarkable finding was that, in two bitches, one of the $6 \mathrm{~h}$ secretory profiles of LH was characterized by frequent increases of short duration. This typical secretory profile of $\mathrm{LH}$ has been reported before in bitches and has been associated with the termination of anoestrus (Concannon $e t$ al., 1986; Concannon, 1993). Indeed, in both bitches, this LH secretory profile was observed a few days before the onset of pro-oestrus. According to Concannon (1993), the period during which increased LH secretion may be observed is brief, perhaps only $4-8$ days, and may not be continuous. The precise role of this increased LH secretion in termination of anoestrus in the bitch remains elusive. There are indications that LH plays an important role in the gonadotrophindependent stage of canine follicle development, because administration of pharmacological doses of LH alone can terminate anoestrus by inducing a follicular phase in bitches (Verstegen $e t$ al., 1997). Sensitivity to FSH is modulated by regulatory substances of thecal cell origin. Since $\mathrm{LH}$ regulates thecal cell function, stimulation by LH may sensitize granulosa cells to FSH indirectly, that is, modulate FSH thresholds (Hillier, 1996).

In agreement with recent observations (Kooistra et al., 1999), FSH and LH pulses were released in concordance, indicating that GnRH is probably the sole hypothalamic releasing hormone for both $\mathrm{LH}$ and FSH in this species. Concurrent secretion of LH and FSH has also been reported in humans (Veldhuis et al., 1992; Genazzani et al., 1993; Booth et al., 1996; Lambalk et al., 1997), rats (Urbanski et al., 1988), mares (Irvine and Alexander, 1993; Silvia et al., 1995), deer (Monfort et al., 1993) and cattle (Schallenberger et al., 1985). However, in most of these species, independent FSH and LH pulses are also observed frequently. In these species, FSH and $\mathrm{LH}$ synthesis and secretion are regulated differentially by the amplitude and frequency of GnRH pulses. A low frequency of $\mathrm{GnRH}$ stimulation increases FSH release preferentially, whereas LH is stimulated optimally by more frequent GnRH pulses (Haisenleder et al., 1991; Shupnik, 1996; Vizcarra et al., 1997). This finding may be explained by the fact that the expression of intrapituitary factors involved in the synthesis of FSH, that is, activin and follistatin, is also dependent on the GnRH pulse frequency (Besecke et al., 1996). Gonadal steroids and gonadal peptides also play a role in the differential or non-parallel secretion of $\mathrm{FSH}$ and $\mathrm{LH}$ (Shupnik, 1996). In addition, the existence of a specific hypothalamic FSH-releasing factor has been demonstrated in the rat (Yu et al., 1997; Koppan et al., 1998).

Despite the coincidence of pulses of LH and FSH, there are differences in basal concentrations and pulse characteristics, indicating that, in bitches, there is differential regulation of the secretion of these hormones. First, progression of anoestrus in bitches is associated with an increase in the basal concentration of plasma FSH concentration, whereas plasma LH remains at the same basal concentrations
(Kooistra et al., 1999). Second, in contrast to the basal plasma LH concentrations, the basal plasma FSH concentrations are relatively low during the follicular phase of the oestrous cycle (Kooistra et al., 1999). In the present study, administration of bromocriptine was also associated with differential regulation of the secretion patterns of FSH and LH. Fourteen days of bromocriptine administration resulted in a significant increase in basal plasma FSH concentration and AUC for FSH, without a concomitant increase in basal plasma LH concentration and AUC for LH. In addition, bromocriptine treatment resulted in FSH pulses with a lower mean amplitude and a shorter mean duration, without influencing the pulse characteristics of LH. Thus, with regard to the interaction between dopaminergic influences and gonadotrophin release, it may be concluded that the effect of bromocriptine is confined to FSH secretion.

In addition to demonstrating the concurrent pulsatile secretion of LH and FSH, the results of the present study demonstrate that the bromocriptine-induced shortening of the interoestrous interval in bitches is associated with an increase in plasma FSH concentration without a concomitant increase in plasma LH concentration. This finding indicates that treatment with the dopamine agonist, bromocriptine, increases plasma FSH concentration to a concentration that results in the enhancement of follicle development. The FSH threshold concept, originally proposed in primates, seems to hold true also for bitches.

The authors are grateful for the technical assistance of D. M. Blankenstein, A. V. P. van de Poll, and Y. W. E. A. Pollak. The authors thank W. E. van den Brom for his valuable assistance with the statistical analysis. The critical reading of the manuscript by $\mathrm{A}$. Rijnberk and B. E. Belshaw is highly appreciated.

\section{References}

Besecke LM, Guendner MJ, Schneyer AL, Bauer-Dantoin AC, Jameson JL and Weiss J (1996) Gonadotropin-releasing hormone regulates folliclestimulating hormone $\beta$ gene expression through an activin/follistatin autocrine or paracrine loop Endocrinology 137 3667-3673

Bevers MM, Willemse AH and Kruip ThAM (1983) The effect of bromocryptine on luteinizing hormone levels in the lactating sow: evidence for a suppressive action by prolactin and the suckling stimulus Acta Endocrinologica 104 261-265

Booth RA, Weltman JY, Yankov VI, Murray J, Davison TS, Rogol AD, Asplin CM, Johnson ML, Veldhuis JD and Evans WS (1996) Mode of pulsatile follicle-stimulating hormone secretion in gonadal hormone-sufficient and -deficient women Journal of Clinical Endocrinology and Metabolism 81 3208-3214

Bouchard G, Youngquist RS, Vaillancourt D, Krause GF, Guay P and Paradis $\mathbf{M}$ (1991) Seasonality and variability of the interestrous interval in the bitch Theriogenology 36 41-50

Brown JB (1978) Pituitary control of ovarian function: concepts derived from gonadotropin therapy Australian and New Zealand Journal of Obstetrics and Gynaecology $1847-54$

Concannon PW (1993) Biology of gonadotrophin secretion in adult and prepubertal female dogs journal of Reproduction and Fertility Supplement 47 $3-27$

Concannon PW, Hansel W and McKentee K (1977) Changes in LH, progesterone and sexual behaviour associated with preovulatory luteinization in the bitch Biology of Reproduction 17 604-613

Concannon PW, Whaley S and Anderson SP (1986) Increased LH pulse frequency associated with termination of anestrus during the ovarian cycle of the dog Biology of Reproduction 34 (Supplement 1) Abstract 119

Dieleman SJ and Schoenmakers HJN (1979) Radioimmunoassays to 
determine the presence of progesterone and estrone in the starfish Asterias rubens. General and Comparative Endocrinology 39 534-542

Genazzani AD, Petraglia F, Volpogni C, D'Ambrogio G, Facchinetti F and Genazzani AR (1993) FSH secretory pattern and degree of concordance with LH in amenorrheic, fertile and postmenopausal women American Journal of Physiology 264 E776-E781

Haisenleder DJ, Dalkin AC, Ortolano GA, Marshall JC and Shupnik MA (1991) A pulsatile gonadotropin-releasing hormone stimulus is required to increase transcription of the gonadotropin subunit genes: evidence for differential regulation of transcription by pulse frequency in vivo. Endocrinology 128 509-517

Hillier SG (1996) Roles of follicle stimulating hormone and luteinizing hormone in controlled ovarian hyperstimulation Human Reproduction 11 (Supplement 3) 113-121

Irvine CHG and Alexander SL (1993) Secretory patterns and rates of gonadotropin-releasing hormone, follicle-stimulating hormone and luteinizing hormone revealed by intensive sampling of pituitary venous blood in the luteal phase mare Endocrinology 132 212-218

Jedlinska M, Rozewiecka L and Ziecik AJ (1995) Effect of hypoprolactinaemia and hyperprolactinaemia on LH secretion, endocrine function of testes and structure of seminiferous tubules in boars Journal of Reproduction and Fertility 103 265-272

Jeffcoate IA (1993) Endocrinology of anoestrous bitches Journal of Reproduction and Fertility Supplement 47 69-76

Kooistra HS, Okkens AC, Bevers MM, Popp-Snijders C, Van Haaften B, Dieleman SJ and Schoemaker J (1999) Concurrent pulsatile secretion of luteinizing and follicle-stimulating hormone during different phases of the estrous cycle and anestrus in beagle bitches Biology of Reproduction 60 65-71

Koppan M, Kovacs M, Mezö I and Flerko B (1998) Electrochemical stimulation of the median eminence evokes FSH but not LH release after LHRH antagonist treatment in vivo and in vitro. Journal of Neuroendocrinology $10231-236$

Lambalk CB, De Boer L, Schoute E, Popp-Snijders C and Schoemaker J (1997) Post-menopausal and chronological age have divergent effects on pituitary and hypothalamic function in episodic gonadotrophin secretion Clinical Endocrinology 46 439-443

Merriam GR and Wachter KW (1982) Algorithms for the study of episodic hormone secretion American Journal of Physiology 243 E310-E318

Monfort SL, Brown JL, Wood TC, Wemmer C, Vargas A, Williamson LR and Wildt DE (1993) Seasonal patterns of basal and GnRH-induced LH, FSH and testosterone secretion in Eld's deer stags (Cervus eldi thamin) Journal of Reproduction and Fertility 98 481-488

Nett TM, Akbar AM, Phemister RD, Holst PA, Reichert LE, Jr and Niswender GD (1975) Levels of luteinizing hormone, estradiol and progesterone in serum during the estrous cycle and pregnancy in the beagle bitch Proceedings of the Society for Experimental Biology and Medicine $\mathbf{1 4 8}$ 134-139

Okkens AC, Bevers MM, Dieleman SJ and Willemse AH (1985a) Shortening of the interoestrous interval and the lifespan of the corpus luteum of the cyclic dog by bromocriptine treatment Veterinary Quarterly 7 173-176

Okkens AC, Dieleman SJ, Bevers MM and Willemse AH (1985b) Evidence for the non-involvement of the uterus in the lifespan of the corpus luteum in the cyclic dog Veterinary Quarterly 7 169-173

Okkens AC, Bevers MM, Dieleman SJ and Willemse AH (1990) Evidence for prolactin as the main luteotrophic factor in the cyclic dog Veterinary Quarterly 12 193-201

Okkens AC, Kooistra HS, Dieleman SJ and Bevers MM (1997) Dopamine agonistic effects as opposed to prolactin concentrations in plasma as the influencing factor on the duration of anoestrus in bitches journal of Reproduction and Fertility Supplement 51 55-58

Olson PN, Bowen RA, Behrendt MD, Olson JD, Nett TM (1982) Concentrations of reproductive hormones in canine serum throughout late anestrus, proestrus and estrus Biology of Reproduction 27 1196-1206

Onclin K, Verstegen J, Silva LDM and Concannon P (1995) Patterns of circulating prolactin, LH and FSH during dopamine-agonist induced termination of anestrus in beagle dogs Biology of Reproduction 52 (Supplement 1) Abstract 314

Park SK and Selmanoff M (1993) Hyperprolactinemia suppresses the luteinizing hormone responses to $N$-methyl-D-aspartate, epinephrine, and neuropeptide $Y$ in male rats Endocrinology 133 2091-2097

Park SK, Keenan MW and Selmanoff M (1993) Graded hyperprolactinemia first suppresses LH pulse frequency and then pulse amplitude in castrated male rats Neuroendocrinology 58 448-453

Saunder SE, Frager M, Case GD, Kelch RP and Marshall JC (1984) Abnormal patterns of pulsatile luteinizing hormone secretion in women with hyperprolactinemia and amenorrhea: responses to bromocriptine Journal of Clinical Endocrinology and Metabolism 59 941-948

Schaefers-Okkens AC (1996) Ovaries. In Clinical Endocrinology of Dogs and Cats pp 131-156 Ed. A Rijnberk. Kluwer Academic Publishers, Dordrecht

Schallenberger E, Schöndorfer AM and Walters DL (1985) Gonadotrophins and ovarian steroids in cattle I. Pulsatile changes of concentrations in the jugular vein throughout the oestrous cycle Acta Endocrinologica 108 312-321

Schoemaker J, Van Weissenbruch MM, Scheele F and Van Der Meer M (1993) The FSH threshold concept in clinical ovulation induction Ballière's Clinical Obstetrics and Gynaecology 7 297-308

Shupnik MA (1996) Gonadal hormone feedback on pituitary gonadotropin genes Trends in Endocrinology and Metabolism 7 272-276

Silvia PJ, Meyer SL and Fitzgerald BP (1995) Pulsatile gonadotropin secretion determined by frequent sampling from the intercavernous sinus of the mare: possible modulatory role of progesterone during luteolysis Biology of Reproduction 53 438-446

Tani H, Inaba T, Tamada H, Sawada T, Mori J and Torii R (1996) Increasing gonadotropin-releasing hormone release by perifused hypothalamus from early to late anestrus in the beagle bitch Neuroscience Letters $2071-4$

Urbanski HF, Pickle RL and Ramirez VD (1988) Simultaneous measurements of gonadotrophin-releasing hormone, luteinizing hormone, and folliclestimulating hormone in the orchidectomized rat Endocrinology 123 413-419

Van Haaften B, Dieleman SJ, Okkens AC, Bevers MM and Willemse AH (1989) Induction of oestrus and ovulation in dogs by treatment with PMSG and/or bromocriptine Journal of Reproduction and Fertility Supplement 39 330-331

Van Haaften B, Bevers MM, Van Den Brom WE, Okkens AC, Van Sluijs FJ, Willemse AH and Dieleman SJ (1994) Increasing sensitivity of the pituitary to $\mathrm{GnRH}$ from early to late anoestrus in the beagle bitch Journal of Reproduction and Fertility 101 221-225

Veldhuis JD, Johnson ML, Seneta E and Iranmanesh A (1992) Temporal coupling among luteinizing hormone, follicle-stimulating hormone, $\beta$ endorphin and cortisol pulse episodes in vivo. Acta Endocrinologica 126 193-200

Verstegen J, Onclin K, Silva L and Concannon P (1997) Termination of obligate anoestrus and induction of fertile ovarian cycles in dogs by administration of purified pig LH Journal of Reproduction and Fertility 111 $35-40$

Vizcarra JA, Wettemann RP, Braden TD, Turzillo AM and Nett TM (1997) Effect of gonadotropin-releasing hormone $(\mathrm{GnRH})$ pulse frequency on serum and pituitary concentrations of luteinizing hormone and folliclestimulating hormone, GnRH receptors, and messenger ribonucleic acid for gonadotropin subunits in cows Endocrinology 138 594-601

Wildt DE, Panko WB, Chakraborty PK and Seager SWJ (1979) Relationship of serum estrone, estradiol-17 $\beta$ and progesterone to $\mathrm{LH}$, sexual behavior and time of ovulation in the bitch Biology of Reproduction $20648-658$

Yazigi RA, Quintero CH and Salameh WA (1997) Prolactin disorders Fertility and Sterility $67215-225$

Yu WH, Karanth S, Walczewska A, Sower SA and McCann SM (1997) A hypothalamic follicle-stimulating hormone-releasing decapeptide in the rat Proceedings National Academy of Sciences USA 94 9499-9503

Zeleznik AJ and Kubik CJ (1986) Ovarian responses in macaques to pulsatile infusion of follicle-stimulating hormone (FSH) and luteinizing hormone: increased sensitivity of the maturing follicle Journal of Clinical Endocrinology and Metabolism 119 2025-2032 